\title{
Robert Cadotte et Anik Meunier L'École d'antan, 1860-1960. Découvrir et se souvenir de l'école du Québec
}

\author{
Québec: PUQ, 2011, 198 p.
}

\section{Jocelyne Murray \\ Chercheuse en histoire}

Dans cet ouvrage, Robert Cadotte et Anik Meunier nous offrent un véritable album de photos illustrant la vie scolaire dans le quartier montréalais d'Hochelaga-Maisonneuve entre 1860 et 1960 . Ces photographies et illustrations perpétuent une exposition en cours au Musée du Château Dufresne du même arrondissement (jusqu'au 25 mai 2012). Les auteurs spécifient d'ailleurs que " ce livre a été rédigé à partir de la recherche effectuée pour préparer l'exposition " (195).

En premier lieu, les auteurs ont réparti cette riche iconographie sous treize thèmes ou chapitres. Le lecteur découvre au fil des pages, entre autres, enseignants et élèves, manuels et matériel scolaire, horaires, fréquentation et activités parascolaires, tant des écoles catholiques que de l'école protestante mixte de ce quartier. Arrêtons-nous à quelques photographies traditionnelles, comme ces classes remplies d'enfants où le maître se tient fièrement à l'arrière de son groupe; d'autres laissent découvrir des élèves en pleine action exposant ainsi une évolution irréversible. Regardez celle-ci prise à la fin du XIX ${ }^{\mathrm{e}}$ siècle, où les écoliers manifestent un sérieux de circonstance (p. 58), puis ceux d'une autre génération qui affichent un air plus décontracté (64). Que dire de ces écolières, cadettes du Sacré-Cœur en réunion (32), à l'air intelligent et arborant un franc sourire? Le contraste est frappant avec la photographie de la page opposée, prise en 1924, montrant un groupe d'Enfants de Marie. À maintes reprises, notre attention est sollicitée par ces illustrations d'époques différentes où l'on peut mesurer les progrès accomplis dans l'appréhension de l'école par les élèves ainsi que dans la diversité des activités parascolaires. De tout temps, les sociétés pieuses, les activités sportives et les fêtes spéciales ont entrecoupé la routine tout en enrichissant la vie sociale des enfants. L'adage "une image vaut mille mots " s'avère ici d'une grande justesse. La partie visuelle de l'ouvrage s'avère fort réussie. 
Les écoles confessionnelles dirigées par des congrégations religieuses enseignantes proposent des activités aux élèves en lien avec leur ferveur religieuse, même la décoration des classes ou le contenu des manuels en témoignent. Heureusement, les auteurs ont pris soin d'accompagner plusieurs photos et objets anciens d'un texte explicatif sans lequel il serait impossible de comprendre certaines bonnes œuvres ou sociétés pieuses disparues de nos jours. Soulignons également l'intérêt de cette " ligne du temps " placée en tête du livre et intitulée 100 ans d'histoire qui relate des faits scolaires marquants simultanément à d'autres événements politiques et sociaux durant la même période.

Cependant, l'aspect visuel de cet ouvrage l'emporte sur la profondeur des textes. En effet, le lecteur reste surpris par les trop courtes introductions des treize chapitres. On y va par " coups de pinceaux » (39), ce qui réduit souvent les propos à des généralités. Le survol ou la simple mention de quelques caractéristiques de notre système d'enseignement place ce livre davantage dans le genre «catalogue d'exposition ». On présente trop succinctement certaines particularités de notre système d'éducation : dualité de l'enseignement catholique ou protestant, programmes d'études partiellement différents pour les filles et les garçons, rémunération des enseignants basée selon le sexe ou l'état civil. Le combat pour la langue français se limite à une levée de fonds pour les écoles francophones ontariennes, rien sur les campagnes du "Bon parler français " qui ont monopolisé tant d'énergie. La section sur les manuels n'est appuyée d'aucune analyse, alors qu'on aurait pu élaborer davantage dans l'intérêt du lecteur peu familier avec ces textes porteurs d'idéologie.

Ainsi, lorsqu'il est question de la gratuité scolaire pourquoi ne pas avoir mentionné qu'en général tous les écoliers payaient une rétribution mensuelle (ou mensualité) qui ne fut abolie qu'avec l'obligation scolaire votée en 1943 tandis que les élèves du secondaire n'en seront exemptés que lors de la réforme de l'enseignement des années 1960 ? Pourtant, le sujet intéressait les commissaires d'écoles montréalais puisque l'obligation scolaire et la gratuité — son corollaire — ont été maintes fois discutées à la CÉCM. Seuls quelques élèves inscrits au cours du soir bénéficieront de la gratuité dès 1910, peut-on lire en page 3 .

D'un autre côté, le choix de certains textes laisse perplexe. Au chapitre de la fréquentation, on peut se demander pourquoi avoir présenté un texte de 1842 dans lequel Jean-Baptiste Meilleur, le premier surintendant de l'Instruction publique (149) garantit au clergé son monopole sur le cours classique réservé à l'élite. C'est sensationnel peut-être, mais on tait une belle innovation de la CÉCM qui implante le cours primaire supérieur et vient briser « le monopole exercé par les collèges classiques sur l'enseignement secondaire " à compter de $1920,{ }^{2}$ geste précurseur pour les programmes d'études de toute la province. Les photographies d'élèves dans leur laboratoire compensent quelque peu ces silences.

Cet ouvrage demeure, malgré ces quelques réticences, un livre agréable à consulter. Il saura intéresser un lectorat assez large parmi lesquels quelques nostalgiques de l'école d'antan ou d'autres intéressés par l'évolution en images de l'école publique. Les chercheurs en éducation pourront y puiser des photographies toujours précieuses. En somme, ce livre crée un nouveau lien visuel entre l'école d'hier et celle d'aujourd'hui. 
228 Historical Studies in Education/Revue d'histoire de l'éducation

\section{Notes}

1 Robert Gagnon, Histoire de la Commission des écoles catholiques de Montréal (Montréal : Boréal, 1996), p. 125-127.

2 Robert Gagno, op.cit., p. 131. 